\title{
The effectiveness of self-care support interventions for children and young people with long-term conditions: a systematic review
}

\author{
S. Kirk, ${ }^{\star}$ S. Beatty, $\dagger$ P. Callery, ${ }^{\star}$ J. Gellatly, $^{\star}$ L. Milnes ${ }^{\star}$ and S. Pryjmachuk ${ }^{\star}$ \\ ${ }^{*}$ School of Nursing, Midwifery and Social Work, University of Manchester, and \\ $†$ School of Community Based Medicine, University of Manchester, Manchester, UK
}

Accepted for publication 26 March 2012

\section{Keywords}

adolescents, children, chronic illness, self care, systematic review

Correspondence: Susan Kirk, School of Nursing, Midwifery and Social Work, University of Manchester, Jean McFarlane Building, Oxford Road, Manchester M13 9PL, UK E-mail: sue.kirk@manchester.ac.uk

\begin{abstract}
Children's health policy has highlighted the need to develop self-care programmes. However, there is a lack of evidence on which to base the development of such programmes. This paper reviews the published research on the effectiveness of self-care support interventions for children and young people with asthma, cystic fibrosis and diabetes. A systematic search was conducted of a range of electronic databases, supplemented by searching the reference lists of retrieved papers and published reviews. Retrieved studies were assessed against quality and eligibility criteria by two independent reviewers. The results were narratively synthesized to examine the effectiveness of self-care support interventions on health status, psycho-social well-being, condition-related knowledge, health service use and participant satisfaction. The search strategy identified 4261 papers which were screened against the review inclusion criteria. A total of 194 papers were assessed as being potentially eligible for inclusion with 15 papers being judged as adequate to include in the review. There is strong evidence of the effectiveness of interventions that target children/young people; use e-health or group-based methods; that are delivered in community settings. There is no evidence that interventions that focus on parents alone or are delivered only in hospital settings are effective. While there is some evidence to inform the development of self-care support programmes, there is a need for well-designed trials of interventions that are feasible to transfer into real-life settings and which involve parents

and children in their development.
\end{abstract}

\section{Introduction}

Self-care is an important component of health policy internationally due to the increasing prevalence of long-term health conditions, recognition of the importance of user involvement and for its potential contribution to controlling escalating health care costs (Wanless 2002; Department of Health 2005). Self-care has been defined in different ways according to who engages in self-care behaviours (individual, family, community); what the context is (health promotion, prevention of illness, limitation of the impact of illness, restoration of health); the activities involved and the extent to which health professionals are involved (Barlow et al. 2002; Department of Health 2005, 2006). A commonly cited definition reflects this range of potential agents, contexts and activities, defining self-care as: 
the actions individuals and carers take for themselves, their children, their families and others to stay fit and maintain good physical and mental health; meet social and psychological needs; prevent illness or accidents; care for minor ailments and long term conditions; and maintain health and wellbeing after an acute illness or discharge from hospital (Department of Health 2005, p. 1).

Although self-care has been mainly examined in terms of individual behaviour, it can be positioned on a continuum, with individually centred components as one end (e.g. health literacy) and social activities at the other (e.g. social capital and public engagement) (Bower et al. 2009). Consequently, the factors influencing self-care can be related to wider contextual influences as well as the individual (Bower et al. 2009). This conceptualization of self-care is presented in Fig. 1.

The goal of self-care support has been interpreted as enabling patients to perform three sets of tasks: medical management of their condition, carrying out normal roles and activities and managing the emotional impact of their condition (Lorig \& Holman 2003). This proposition reflects how self-care support has largely been constructed in terms of the individual patient rather than at the structural constraints influencing self-care. Self care can be supported in a number of ways; through the development of positive patientprofessional relationships; provision of accessible information and education to increase knowledge and skills; support in accessing and navigating the service system (including lay/peer support networks) and self-management support via a range of tools and resources (e.g. telephone help lines, computerbased tools, devices for self-monitoring and personalized selfcare plans)(Corben \& Rosen 2005; Department of Health $2005,2008)$. However, the importance of flexibility in provision has been highlighted in order that individual patients/ users can access a range of different types of support from both formal and informal self-care resources that takes account of their socio-economic and cultural context (Bury et al. 2005). It has also been noted that supporting self-care requires a comprehensive approach, involving interventions that are directed at professionals and health systems as well as patients (Kennedy et al. 2007).

Long-term conditions in childhood are increasing in prevalence. Children face a lifetime of condition management and their success in this may influence health outcomes in adulthood. In addition, the self-care context in relation to children is complex due to the role played by parents in managing their children's long-term conditions and the influence of peers (Christian et al. 1999; Prout et al. 1999; D'Auria et al. 2000).
Consequently, the 'self' in this context is a combination of the child/young person and parents.

Although children's health policy has highlighted the need for services to support self-care and for self-care programmes to be developed (Department of Health, Department for Education and Skills 2004; Department of Health 2009) little is known about the appropriateness and effectiveness of self-care support for children. Systematic reviews suggest that there is limited evidence of effectiveness for a range of condition-specific interventions; written asthma action/self-management plans (Toelle \& Ram 2004; Bhogal et al. 2006), psychosocial interventions in diabetes and asthma (Hampson et al. 2001; Yorke et al. 2005), diabetes education (Hampson et al. 2001; Couch et al. 2008) and family therapy in asthma (Yorke \& Shuldham 2005). Although there are also reviews that suggest that psychosocial, behavioural and educational interventions may improve outcomes for children with asthma and cystic fibrosis (Wolf et al. 2002; Glasscoe \& Quittner 2008).

As part of a larger study evaluating self-care support for children and young people with long-term conditions (Kirk et al. 2010) a systematic review was conducted to review the published research on the effectiveness of self-care support interventions. The aim of the review was to assess the effectiveness of self-care support interventions (and their components) in relation to childhood long-term conditions. The review question was 'what types of self-care interventions are effective for children/young people aged $0-16$ years with the long-term conditions of asthma, cystic fibrosis (CF) and diabetes?' In the context of this review effectiveness was defined as the extent to which an intervention had a beneficial effect on health-related outcomes. Unlike previous reviews, the review reported in this paper aimed to include a range of self-care support interventions in terms of their target (e.g. child, parent, health care professional), location of delivery, leadership (lay or professional) and medium (face-to-face, e-health) in order to compare different approaches. Conditions were selected that differed in terms of the complexity of self-care management and prognosis. We aimed to compare similarities and differences in interventions and their effectiveness in relation to these different conditions and contexts.

\section{Methods}

\section{Search methods}

A range of electronic databases were searched for relevant studies published between 1 January 1995 and 30 September 2010. These were MEDLINE, PubMed, EMBASE, Scopus, Social 


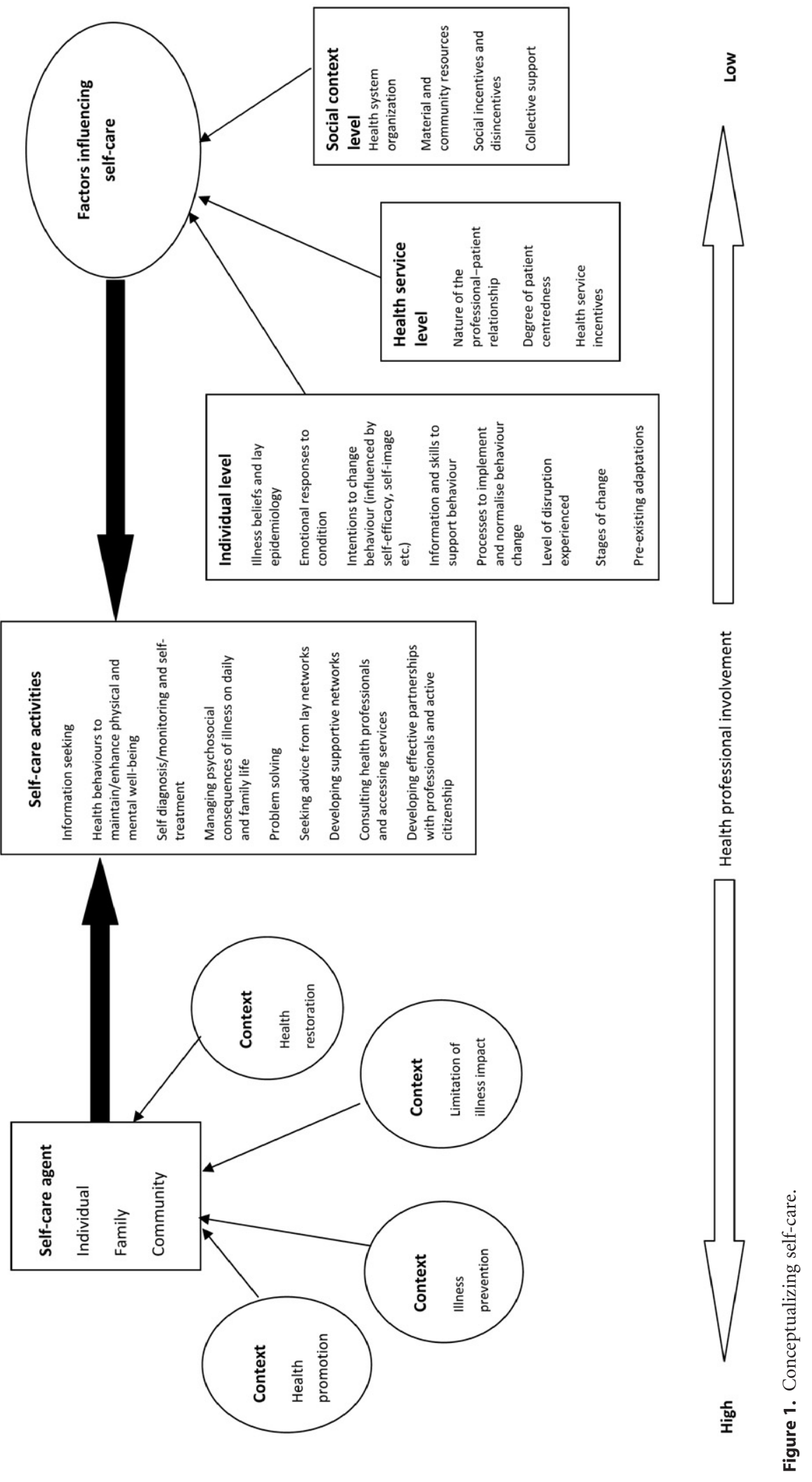


(self manag\$ OR self care OR self help OR collaborative care OR collaborative manag\$) AND (plan OR checklist OR coach\$ OR educationa materials OR goal set\$ OR individual\$ goal\$ OR action plan\$ OR group education OR patient education OR information OR patient held record OR training OR skills train\$ intervention OR program\$ OR patient involv\$ OR patient participat\$ OR share\$ decision making OR decision aid\$ OR diet\$ OR exercise OR telecare OR telehealthcare OR telemedicine OR telemonitor\$ OR home monitor\$ OR telephone support OR virtual communit\$ OR mutual support OR peer support OR self admin\$ OR self monitor\$ OR self medicat\$ OR self diagnosis OR self treatment OR provider training OR provider education) AND (child\$ OR bab\$ OR infant OR toddler OR teenager\$ OR adolescen\$ OR young person OR young people OR youth OR juvenile OR pediatric OR paediatric OR parent\$ OR mother OR father OR guardian OR advocate OR carer OR family) AND (diabet\$ OR cystic fibrosis OR mucoviscidosis OR asthma)
Table 1. MEDLINE search

ity for self-care and/or improve their health. The target of the intervention, needed to be actively involved and engaged in the intervention, rather than be a passive recipient of knowledge or instructions.

\section{Language}

- Only studies published in English were included in the review.

\section{Exclusion criteria}

- Mean age of children/young people above 16.5 or if any individual young person was older than 21 .

- No active involvement of participants in the intervention.

Sciences Citation Index, Sociological Abstracts, Applied Social Sciences Index and Abstracts (ASSIA), Social Care Online, Social Services Abstracts, Child Data, Cumulative Index to Nursing and Allied Health Literature (CINAHL), British Nursing Index, Allied and Complementary Medicine (AMED), PsycInfo, Health Management Information Consortium (HMIC), The Cochrane Library, The North West Grey Literature Service (FADE). The search terms included MeSH and 'free text' terms in combination and was adapted according to the particular database. The MEDLINE search is presented in Table 1 . In addition, reference lists of retrieved papers and published reviews were searched for potentially relevant papers. Unpublished data were not sought from authors due to time limitations.

\section{Inclusion criteria}

Type of study

- Randomized controlled trials.

\section{Types of participants}

- Studies focusing on children and young people aged 0-16 years diagnosed with one of the following long-term conditions: asthma, cystic fibrosis and diabetes.

- Studies involving or focusing on parents, peers or professionals that related to the above long-term conditions and age group.

\section{Types of interventions}

- Any intervention aiming to help children/young people take control of and manage their condition, promote their capac-

\section{Data extraction and quality review}

The abstracts of the retrieved papers were screened to eliminate those that did not meet the review inclusion criteria. If it is was unclear from the abstract whether papers met the inclusion criteria full paper manuscripts were obtained. Each paper that passed the initial screening process was read and assessed independently for quality and eligibility by two reviewers from the research team and data were extracted using a detailed data extraction form based on those developed by the Centre for Reviews and Dissemination (2001) and Marshall and colleagues (2005). The methodological quality of studies was assessed in relation to their internal validity and analysis (Centre for Reviews and Dissemination 2001). Any discrepancies in assessments that could not be resolved by discussion and consensus were resolved by arbitration by a third independent reviewer. The quality assessment of the included studies is summarized in Table 2.

\section{Results}

The search strategy identified 4261 papers which were screened against the review inclusion criteria. A total of 194 papers were assessed as being potentially eligible for inclusion (Fig. 2). These papers were reviewed for quality and eligibility and 15 papers describing 13 studies were judged as adequate to include in the review. Figure 2 shows the numbers of papers at each stage of the screening and reviewing process.

\section{Description of the included studies}

The characteristics of the 13 studies (design, type of intervention and results) are summarized in Table 3. The majority 


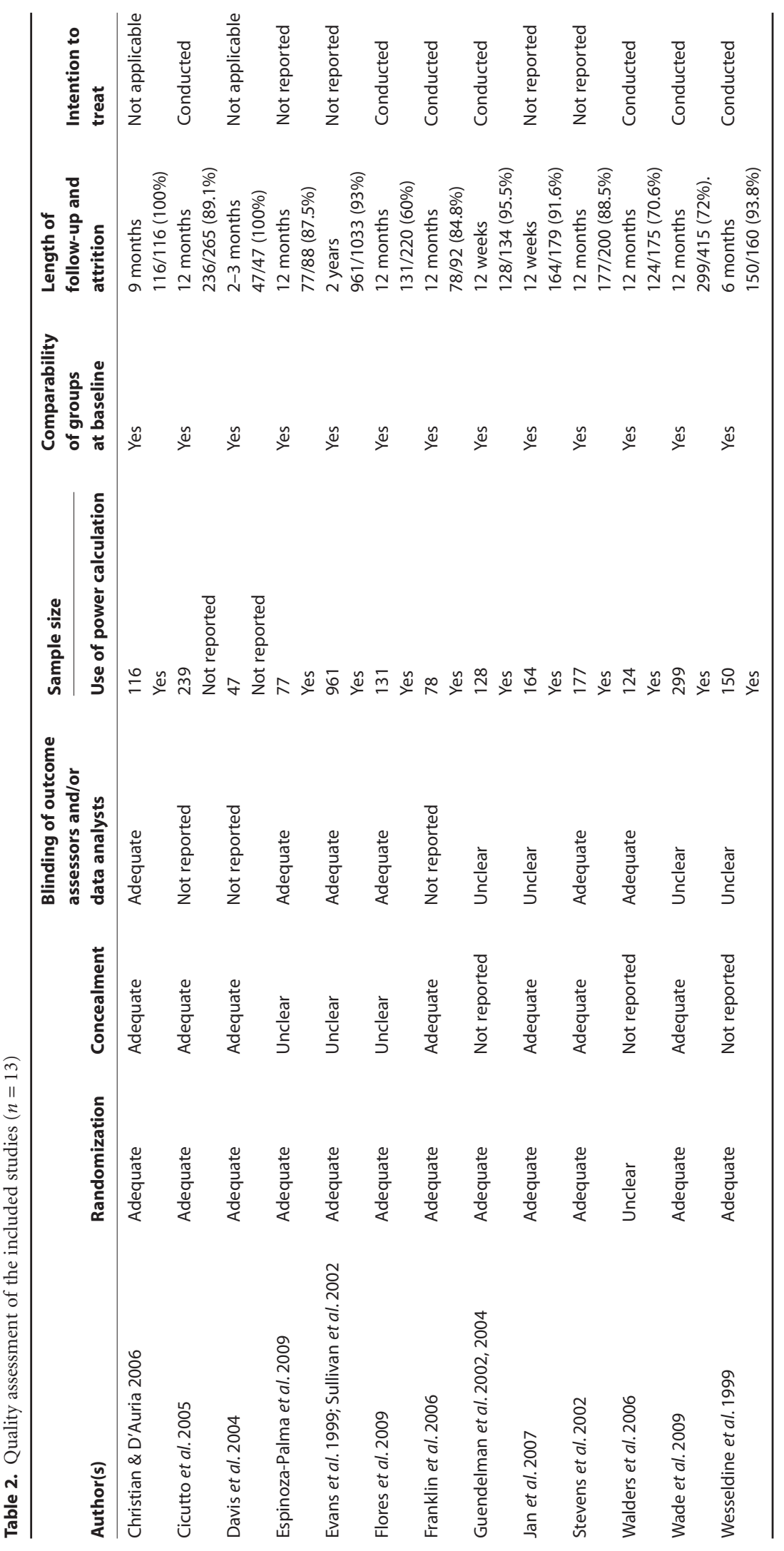




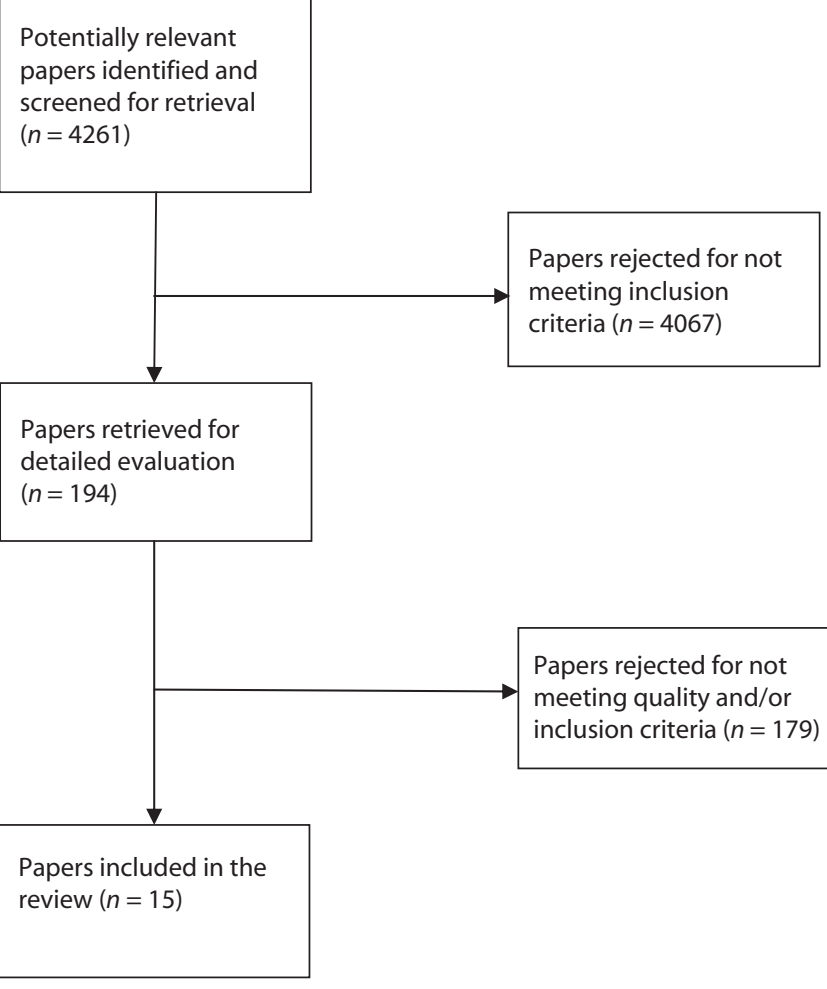

Figure 2. Number of papers screened, assessed and included.

$(n=12)$ of studies compared one intervention with one control. One study compared two interventions with one control. Sample sizes ranged from 47 to 1033 . Follow-up periods ranged from 2 months to 2 years with the most common follow-up period being between 12 and 14 months $(n=8)$. Six studies were conducted in the USA, three studies in the UK, two in Canada and one in each of Chile and Taiwan.

\section{Participants}

Overall, the age-range covered was 2 to 18 years, with one intervention aimed only at children under 6 years old (Stevens et al. 2002) and one aimed only at adolescents/teenagers (Franklin et al. 2006). Most interventions were aimed at children/young people either within the primary school age range $(n=4)$ or across the primary and secondary school age range $(n=7)$. All studies included both genders. Where data on the gender and ethnicity of participants were clearly reported, the majority of studies had a higher proportion of male children and a higher proportion of White participants in their samples (excluding three studies that focused only on ethnic minority children/ young people or those living in inner-city areas).

\section{Self-care interventions}

The majority of the studies $(n=10)$ focused on asthma, with two being on cystic fibrosis and one on diabetes. Five studies targeted the child/young person only and seven focussed on the child/young person and their parent/carer. Two asthma studies were targeted at children/young people from urban/inner-city areas (Evans et al. 1999; Sullivan et al. 2002; Guendelman et al. 2002,2004 ) and one study focussed only on ethnic minority children/young people (Flores et al. 2009).

Studies investigated a wide range of interventions and outcomes but all included some element of education or training of the child, parent/family or professional as an intervention component. Other components included behavioural therapy, enhancing communication between children and parents/ health care professionals, problem-solving skills, counselling and support (Table 3 ). The aims of the interventions can be classified as enhancing self-management $(n=10)$; developing coping/problem-solving/social skills $(n=2)$; improving communication skills $(n=2)$ and reducing health service use $(n=2)$.

The setting for six studies was the hospital, five studies were provided in the home/community and one intervention was school-based (Table 3). In one study elements of the interventions were delivered in both the clinic and home (Christian \& D'Auria 2006).

The majority of the interventions $(n=8)$ were delivered to an individual child or family but in two studies the intervention was delivered on a group basis and three interventions used a combination of individual and group processes (Table 3). In five studies the intervention was delivered via an e-health ${ }^{1}$ mode of delivery. This included computers (e.g. CD ROMs or Internet), text-messaging systems and telephone support and education.

Ten interventions reported no explicit underlying theoretical basis. Where a theoretical basis was reported the theories identified were social cognitive theory $(n=2)$, self-regulation $(n=1)$, developmental theory $(n=1)$ and social ecological theory $(n=1)$. One intervention was led by trained parent mentors (Flores et al. 2009).

\section{Outcomes assessed}

The studies assessed a wide range of outcomes in evaluating the effectiveness of the interventions with nine identifying a clear primary outcome. The most commonly assessed outcomes were health status $(n=11)$, health service utilization $(n=10)$,

\footnotetext{
${ }^{1}$ E-health is the use of emerging information and communications technology, especially the Internet, to improve or enable health and healthcare (Eng 2001).
} 


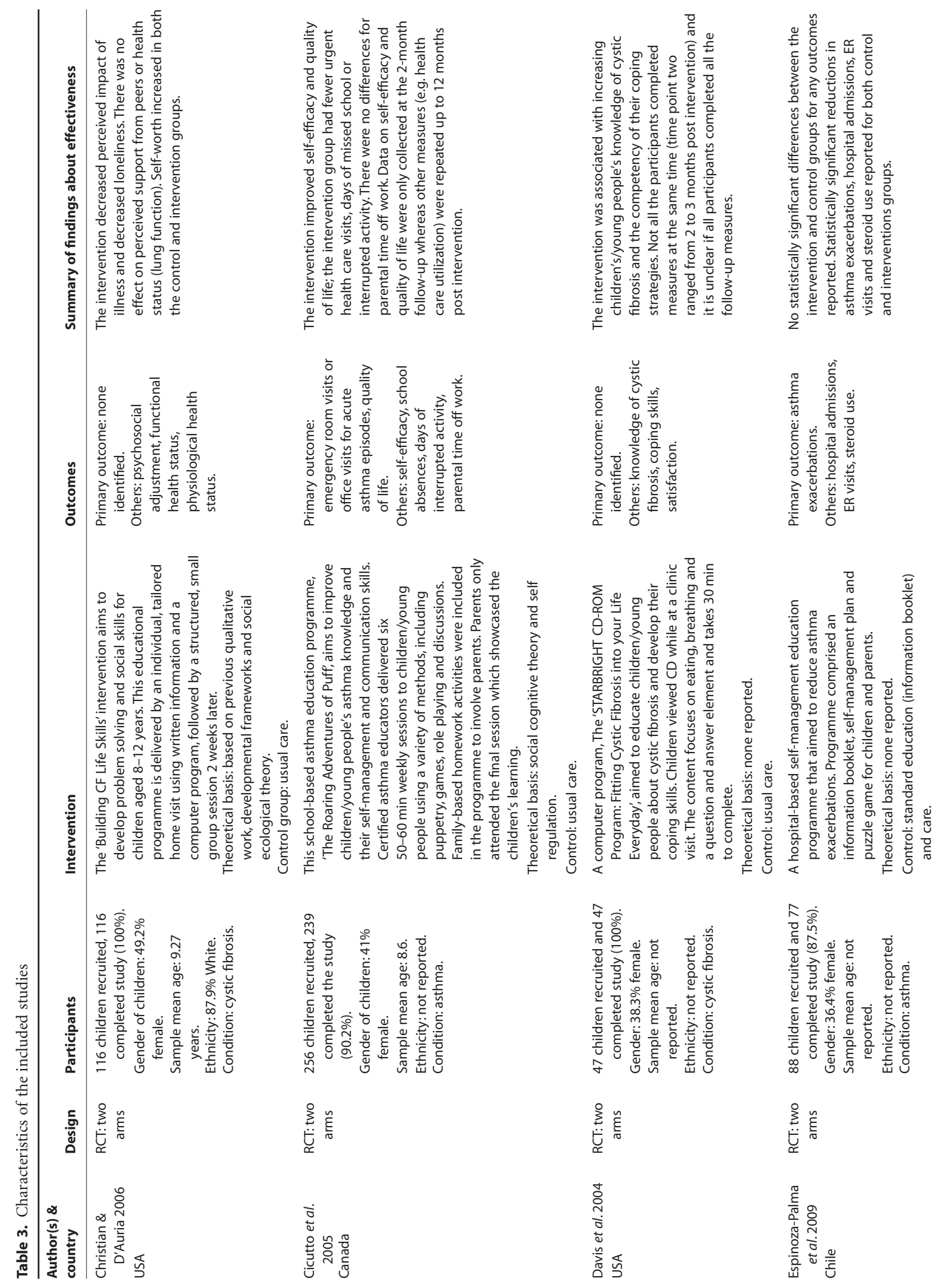




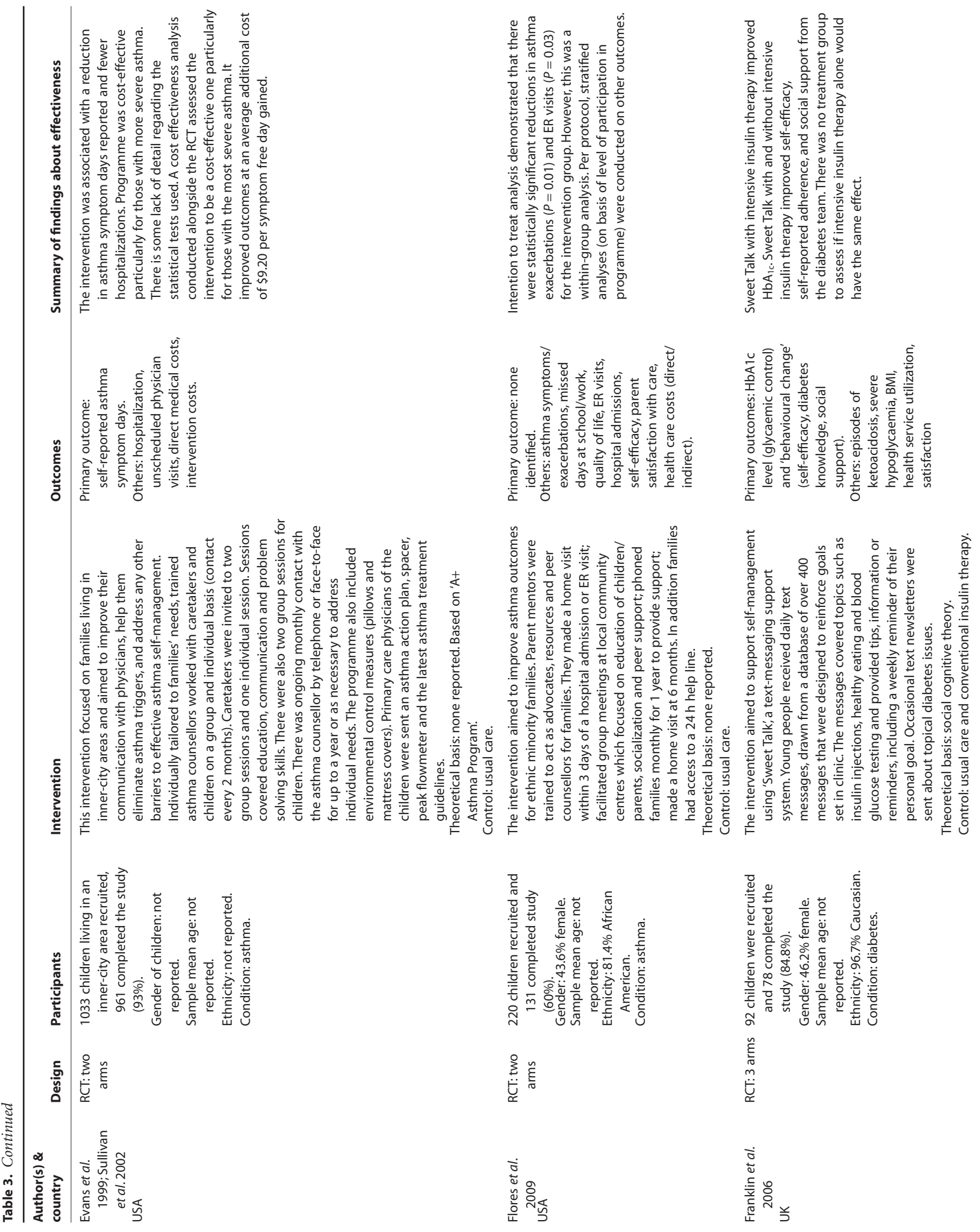



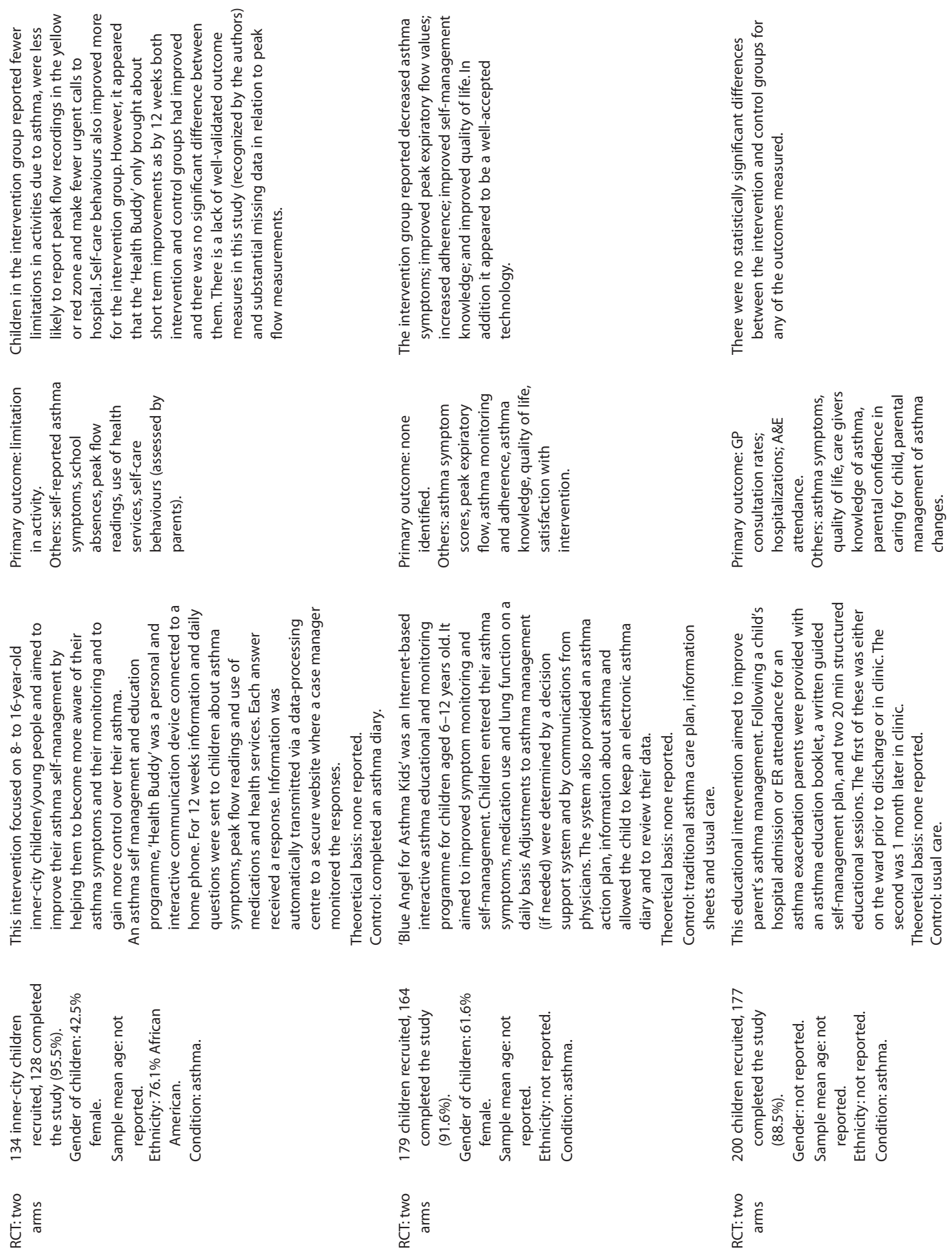

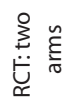
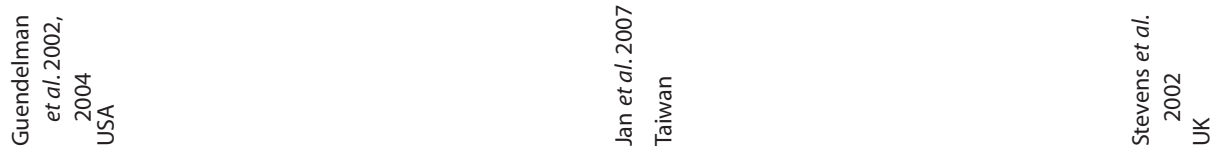


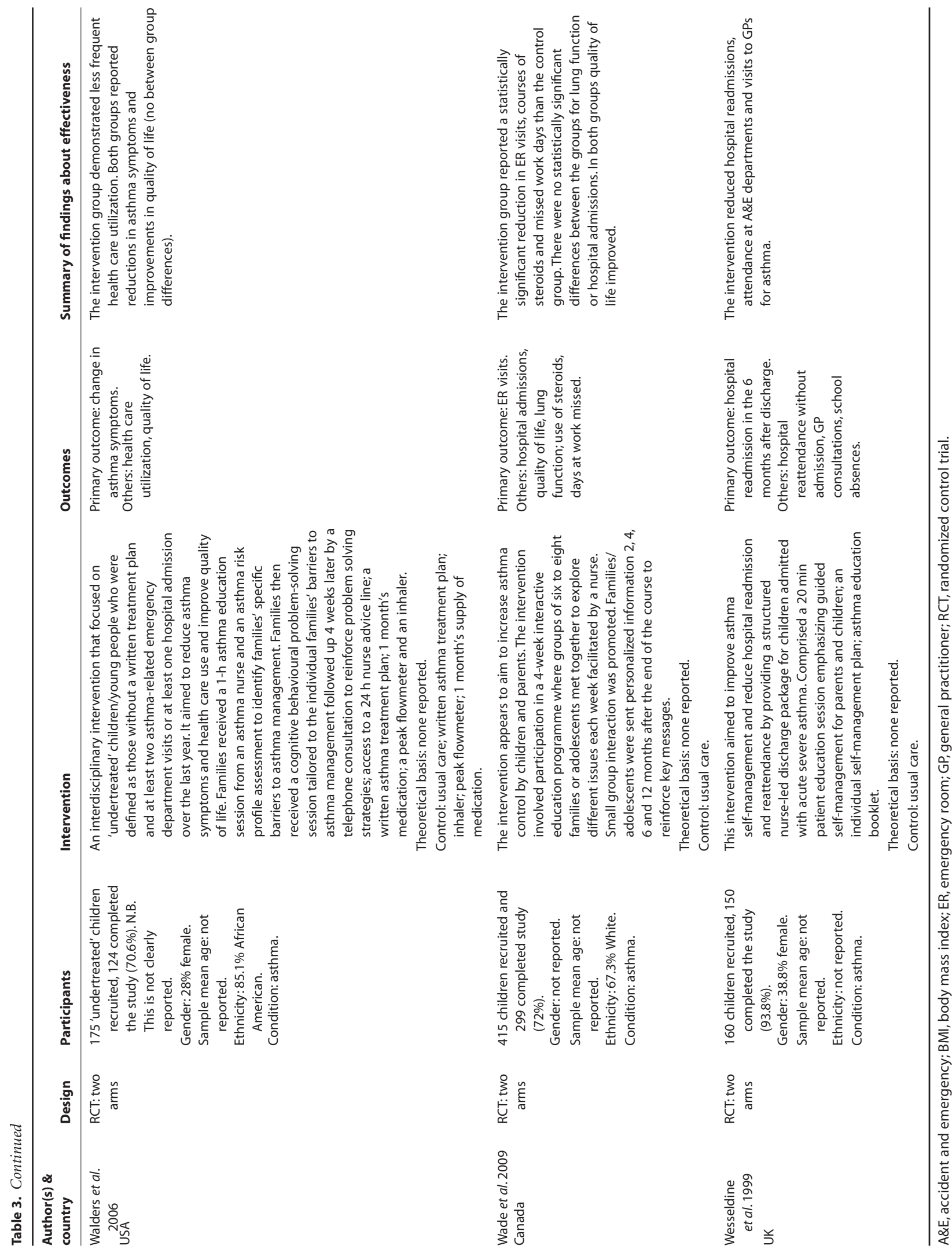


psychosocial well-being $(n=7)$ and condition related knowledge $(n=4)$ (Table 3$)$. Only a minority of studies included an assessment of participant satisfaction $(n=4)$ or health care or intervention costs $(n=2)$.

\section{Methodological quality}

The methodological quality assessment of the 13 studies included in the review is presented in Table 2. Twelve studies reported an adequate method of randomization as defined by Higgins and Green (2008). In one study the randomization method was unclear (Walders et al. 2006). Seven studies reported their method of allocation concealment in sufficient detail to be reasonably certain of its adequacy. While it may not be possible to fully blind participants to their allocation group in interventions such as these, only four studies described blinding of outcome assessors and/or care providers which is a source of potential bias for studies not assessing outcomes by postal questionnaires. All the included studies provided information on follow-up rates with seven achieving a rate of $90 \%$ or over. The conduct of an Intention To Treat analysis was reported in nine studies. All studies reported equivalent study groups at baseline. The length of follow-up was 12 months or more in eight studies. Ten studies reported that a power calculation had been conducted prior to the commencement of the study.

Interventions often incorporated multiple components and as a consequence a wide variety of outcomes were reported. Many studies measured multiple outcomes but only nine clearly identified a primary outcome (Table 3 ). There was a high reliance on self-report measures without a discussion of their limitations and parents were used as proxies for their children. In some studies it was unclear who administered the questionnaires and measurement tools and who completed them. Only one asthma study took account of seasonal or daily variations in asthma (Evans et al. 1999; Sullivan et al. 2002). A wide range of tools were used to measure outcomes and in some studies there was a lack of reporting of their reliability and validity. None of the studies included an integral process evaluation and relatively few studies looked at satisfaction or participant views on the intervention. In a number of studies not all the potential benefits of programmes were measured, for example, social support benefits, knowledge gain (e.g. Evans et al. 1999; Sullivan et al. 2002; Espinoza-Palma et al. 2009). Moreover, in a number of studies there was a lack of detail about the interventions themselves and how they were implemented. While many studies included a wide age range of children it was unclear if or how interventions were adapted to make them age appropriate (e.g. Flores et al. 2009).

\section{The effect of interventions on outcomes}

The heterogeneity of the studies, interventions and outcomes prevented a meta-analysis being conducted and hence the findings from the review are reported as a narrative synthesis. In this section the effectiveness of the interventions will be considered in relation to the outcomes of health status, psychosocial wellbeing and health behaviour, knowledge, health service utilization and cost-effectiveness and satisfaction.

\section{Health status}

Health status was an outcome measured by 11 studies but was conceptualized and measured in different ways in relation to the particular condition (Table 4). The outcomes measured included symptom reduction (asthma), lung function (asthma), limitations on usual activities/physical functioning (asthma, cystic fibrosis) and glycaemic control (diabetes). As shown in Table 4, health status was reported on by children/young people themselves and parents. In one study physiological measures were taken by the researchers. In five studies the intervention was effective in improving health status (Evans et al. 1999; Guendelman et al. 2002, 2004; Sullivan et al. 2002; Cicutto et al. 2005; Jan et al. 2007; Wade et al. 2009). In a further study the intervention was effective when coupled with intensive insulin therapy (Franklin et al. 2006). Of the effective interventions, six were delivered in a home/community setting (Evans et al. 1999; Guendelman et al. 2002, 2004; Sullivan et al. 2002; Cicutto et al. 2005; Franklin et al. 2006; Jan et al. 2007), three targeted both children/young people and parents (Evans et al. 1999; Sullivan et al. 2002; Cicutto et al. 2005; Wade et al. 2009) and three focused on children/young people alone (Guendelman et al. 2002, 2004; Franklin et al. 2006; Jan et al. 2007) (Table 5). Three of the effective interventions used e-health modes of delivery and included some form of interaction with a health care professional or individualized computerized feedback (Guendelman et al. 2002, 2004; Franklin et al. 2006; Jan et al. 2007).

\section{Psychosocial well-being and health behaviour}

A range of different psychosocial aspects of living with a longterm condition were used as outcomes with the commonest being quality of life $(n=6)$ and self-efficacy $(n=3)$. Interventions were associated with improvements in children's/young people's self-efficacy (Cicutto et al. 2005; Franklin et al. 2006) and quality of life (Cicutto et al. 2005; Jan et al. 2007; Wade et al. 2009) (Table 4). However, three studies found that the 


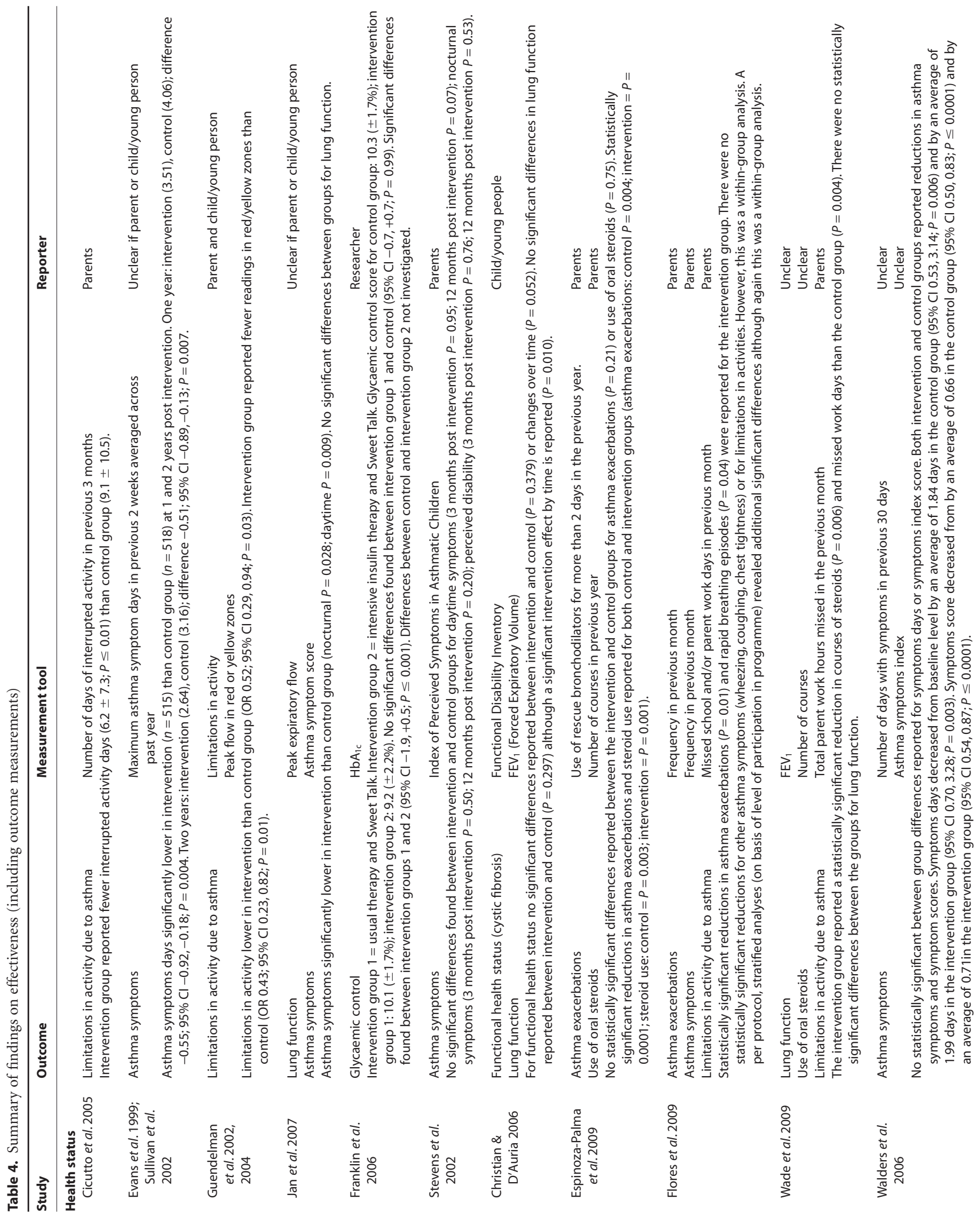




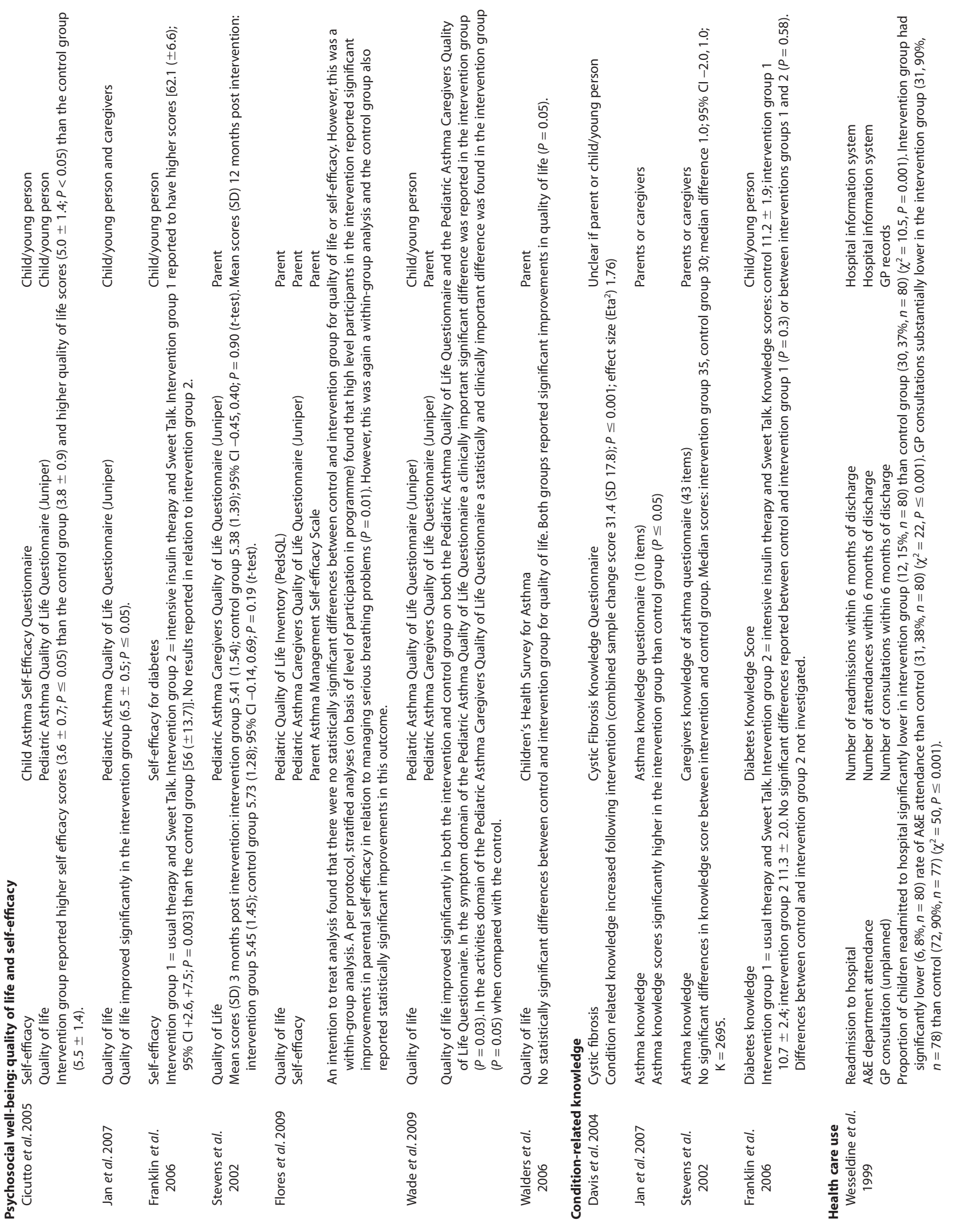




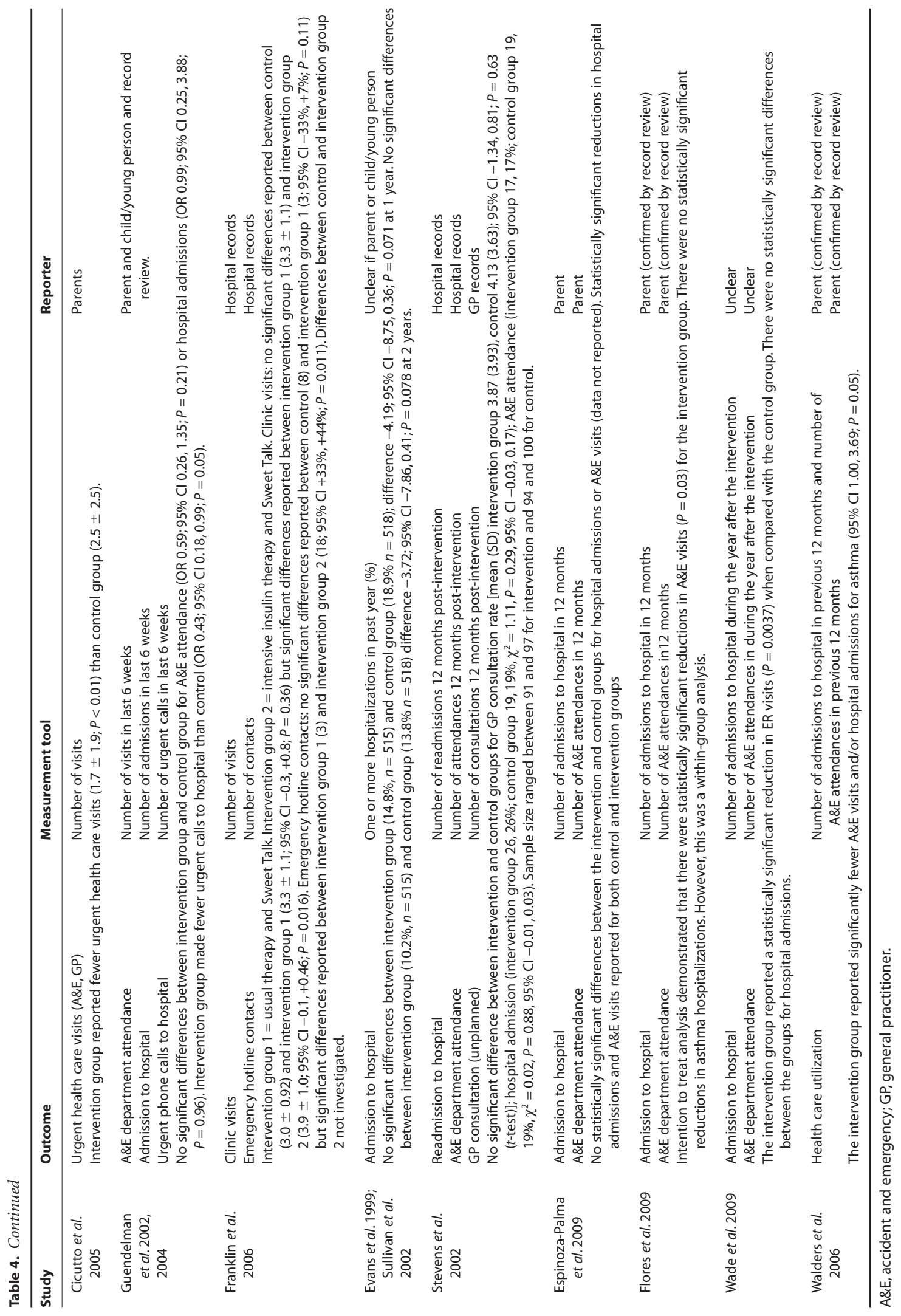


intervention had no effect on parental quality of life (Stevens et al. 2002; Walders et al. 2006; Flores et al. 2009).

In relation to other psychosocial well-being/health behaviour outcomes, one intervention was associated with a short-term (12 week) improvement in adherence to prescribed medications based on caregiver assessments (Guendelman et al. 2002, 2004). Similarly, Franklin and colleagues (2006) found improved selfreport adherence scores in the groups receiving the intervention. Interventions were also reported to be effective in improving coping skills (Davis et al. 2004), perceptions of illness impact (Christian \& D'Auria 2006) and loneliness (Christian \& D'Auria 2006). Five of the effective interventions were targeted at children/young people only and also used e-health methods (Guendelman et al. 2002, 2004; Davis et al. 2004; Christian \& D'Auria 2006; Franklin et al. 2006; Jan et al. 2007). Two interventions that were associated with improving psychosocial well-being outcomes were focused on children/ young people and parents (Cicutto et al. 2005; Wade et al. 2009).

\section{Knowledge}

All the interventions had an educational element but only four included condition-related knowledge as an outcome (Table 4). Two studies that used e-health type interventions found that children's/young people's knowledge had increased significantly following the intervention (Davis et al. 2004; Jan et al. 2007). Two studies found no significant increase in parental (Stevens et al. 2002) or children's/young people's (Franklin et al. 2006) knowledge.

\section{Health care use and costs}

The effect of the intervention on health service use was measured in 10 studies largely by parental self-report and record review (Table 4). Four studies found that the intervention had no effect on hospital admission while three others reported either significant reductions in admissions (Wesseldine et al. 1999; Walders et al. 2006) or reductions approaching statistical significance (Evans et al. 1999; Sullivan et al. 2002). The effect of interventions on use of Accident and Emergency Department attendance and general practitioner/primary care consultations is mixed with four studies reporting the intervention significantly decreased use (Wesseldine et al. 1999; Cicutto et al. 2005; Walders et al. 2006; Wade et al. 2009) and four studies reporting no effect (Guendelman et al. 2002, 2004; Stevens et al. 2002; Espinoza-Palma et al. 2009; Flores et al. 2009). Another study reported a significant increase in clinic visits and calls to an emergency hotline for the intervention group, however, the frequency of visits were within clinical guidelines (Franklin et al. 2006). Indeed, this increase was seen in a positive light with the intervention demonstrating its potential to encourage attendance.

Cost-effectiveness was only assessed in two studies (Evans et al. 1999; Sullivan et al. 2002 and Flores et al. 2009). The multisystemic intervention evaluated by Evans and colleagues (1999)/ Sullivan and colleagues (2002) was concluded to be costeffective particularly for those with the most severe asthma. Flores and colleagues (2009) reported cost savings for all intervention participants, with an overall cost saving of $\$ 46.16$ per child per month for high level participants.

\section{Individual experience}

Alongside quantitative measures of effectiveness, four studies obtained participants' views on the intervention (Davis et al. 2004; Franklin et al. 2006; Jan et al. 2007; Flores et al. 2009). A text messaging service for children/young people with diabetes was seen as helpful by the majority of users $(81 \%, n=51)$ and 57 $(90 \%)$ reported that they wanted to continue using it after the end of the trial (Franklin et al.2006). One study which provided children/young people with CDs with information about their condition reported high levels of satisfaction with the intervention (Davis et al. 2004) with participants reporting that this method was an appropriate way of obtaining information about their condition. However, limited details are provided by these studies about the conduct of this component of the studies and the results obtained. A study examining parental satisfaction using the Asthma Satisfaction Survey found no significant differences between control and intervention (Flores et al. 2009). Another study obtained feedback from children and parents in the form of a post-intervention survey and found that parents were 'reasonably satisfied' with an Internet-based approach (Jan et al. 2007).

\section{Effectiveness of different types of interventions}

While acknowledging that there are differences in outcome measurement, there is some evidence to suggest that particular interventions may be more effective in improving outcomes (Table 5). It appears that interventions that target children/ young people alone or with their parents/families demonstrate effectiveness across all the outcome categories (Table 5). In particular there is strong evidence that interventions that target children/young people are effective in improving psychosocial well-being. There is no evidence that interventions that only focus on parents are effective. 


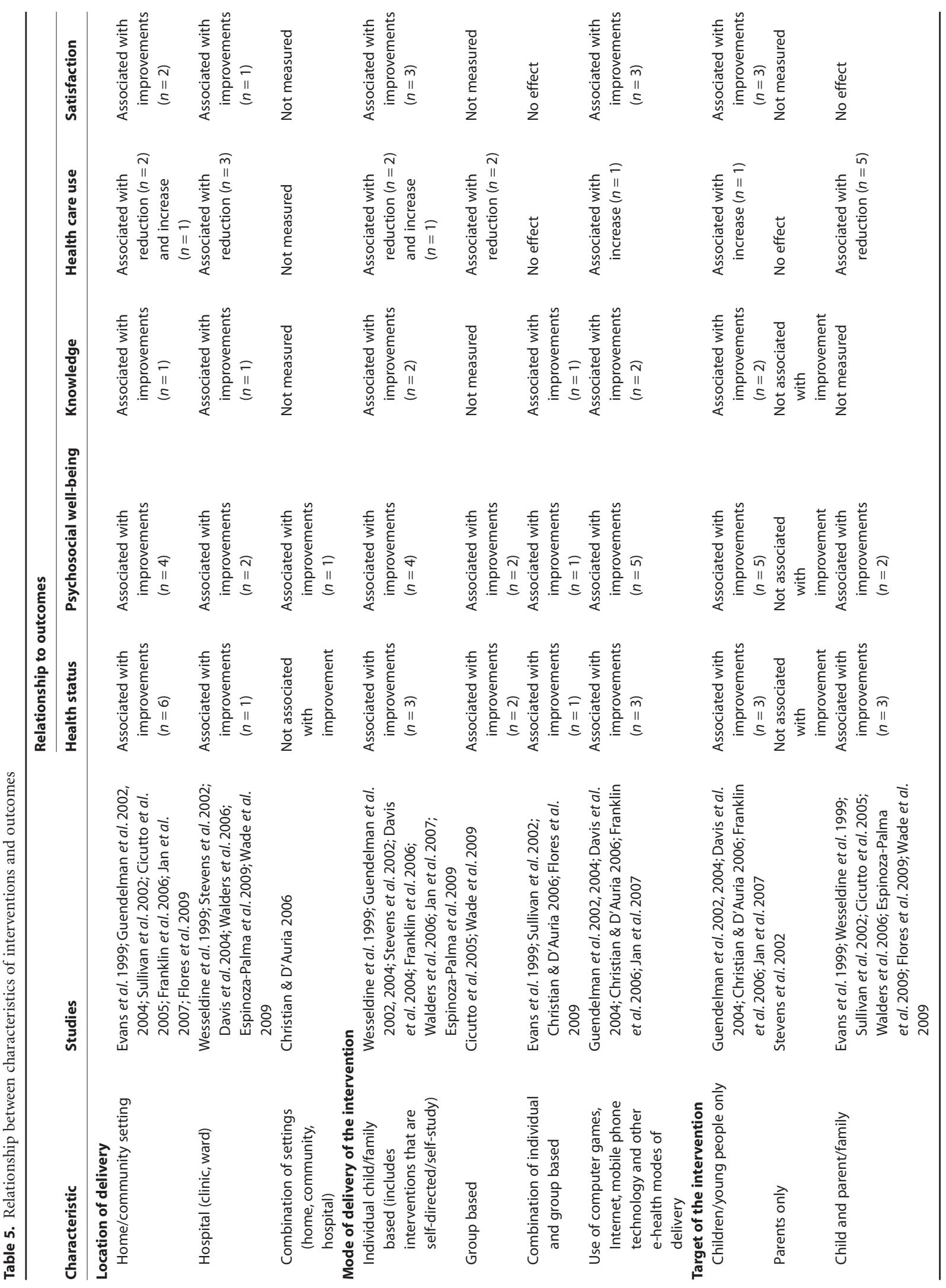


E-health interventions demonstrated positive effects on all outcome categories apart from health service use where their effect is less clear (Table 5). There is strong evidence of the effectiveness of this method of self-care support on psychosocial well-being. Although only two of the included studies investigated a purely group-based intervention both these studies demonstrated effectiveness in terms of improving health status and psychosocial well-being and in reducing health service use (Cicutto et al. 2005; Wade et al. 2009). There is less evidence that interventions that focus on individual children or families are effective (Table 5).

Interventions delivered in the home or in community settings demonstrated effectiveness across all the outcome categories but particularly in relation to health status and psychosocial well-being (Table 5). There is less evidence that combining intervention settings or modes of delivery has a positive effect on outcomes. There is no evidence of the effectiveness of delivering interventions only in hospital settings.

\section{Discussion}

This review suggests that self-care support interventions that target children/young people either alone or with their parents can be effective in improving a range of outcomes and that there is strong evidence for the effectiveness of those interventions directed at children/young people in improving psychosocial well-being. In terms of type of self-care support interventions, there is evidence that those using e-health methods are effective particularly in relation to psychosocial well-being. There is also evidence of the effectiveness of group-based interventions in improving health status and psychosocial well-being and in reducing health service use. There is less evidence that interventions that focus on individual children/families or which combine different intervention settings or modes of delivery are effective. In addition, there is no evidence that interventions that only focus on parents or are delivered only in hospital settings are effective.

Within the wider literature there is conflicting evidence regarding the effectiveness of group-based interventions in relation to self-care with some reviews concluding that group-based approaches are more effective than individual approaches (Deakin et al. 2005; Loveman et al. 2008) and others finding no difference between the two approaches (Barlow et al. 2002; Wolf et al. 2002; Gary et al. 2003). In relation to educational and psychosocial interventions for children with diabetes, beneficial effects have been reported for both individual and group approaches (Hampson et al. 2001). Previous research has suggested that young people and parents value the opportunity to interact with others in a similar situation in order to share common experiences and information (Johnson et al. 2001; Bruzzese et al. 2004; Trollvik \& Severinsson 2005; Barlow et al. 2007). However, the potential negative consequences of peer groups in self-care support have also been noted (Rogers et al. 2009).

E-health appears to be an effective self-care approach in adult chronic illness (Murray et al. 2005; Griffiths \& Christensen 2006). Studies suggest that it is a medium that engages children/ young people and is perceived to support their selfmanagement (Johnson et al. 2001; Gammon et al. 2005; Carroll et al. 2007; Van der Meer et al. 2007). Another review has indicated that while there is evidence to support the provision of self-care support for children in the home there is insufficient evidence in relation to community settings (Norris et al. 2002).

Although the level of detail provided about the interventions reviewed in this paper varied, the transferability of some interventions to 'real-life' settings appears to be feasible in terms of the resources required for integration into current practice (Wesseldine et al. 1999; Jan et al. 2007; Wade et al. 2009). However, there were others that appear to demand significant resources (Evans et al. 1999; Sullivan et al. 2002; Flores et al. 2009). The interventions studied have been developed and implemented under experimental conditions which may be very different from the settings or populations in which they would be actually delivered. Another difficulty in assessing transferability is a lack of reporting of sample characteristics to allow assessments to be made about how representative the sample might be of the population in question. It was notable that in a number of studies there were a disproportionately high number of boys and a low proportion of ethnic minority participants. In addition, a number of studies included a wide age range and it was unclear if interventions were adapted for children and young people of different ages. Although the importance of 'whole system' approaches to self-care are increasingly recognized (Kennedy et al. 2007), currently there is little evidence of their effectiveness in relation to children.

In terms of methodological quality only 15 of the 194 papers reviewed were assessed as being of sufficient methodological quality to produce reliable results or make firm conclusions on effectiveness. Most of the included studies lacked a theoretical basis to the intervention developed. A theoretical basis is important because it suggests the nature and content of the intervention as well as the appropriate outcomes to measure and at what time points. It also informs predictions about which outcomes are expected to change and which are expected to be stable. In some studies the outcomes measured were unclearly defined and not all identified a primary outcome. Where a primary 
outcome was identified this was frequently health status and/or health service. Psychosocial well-being and health behaviour related outcomes were only measured in half of the studies and condition related knowledge in only four studies. However, it can be argued that self-care support interventions are essentially psychosocial and educational interventions concerned with changing self-management behaviours, attitudes and beliefs, which are viewed as being the mediators of improved health status. Therefore, it would seem to be important that intervention studies assess changes in these behavioural and psychological outcomes. Moreover, parents and children/young people are likely to value improvements in their experiences of living with a long-term condition as well as improvements in health status which means that outcomes such as quality of life, self-efficacy and psychological well-being need to be included in assessing the effectiveness of interventions. This suggests that there is a need to ensure that outcome measurement is patient-centred and involves parents and children/young people to ensure interventions are assessed by criteria that are relevant to them. Although some studies included children's/young people's reports, others used parents as proxies without justification even though there is evidence to suggest that parents and children can assess outcomes differently (Upton et al. 2005; Palermo et al.2008). In addition, there were studies where it was unclear who had actually completed the measures.

The review has identified that there is a need for welldesigned randomized control trials to be conducted which test theoretically informed interventions that have been developed with parents and children/young people and which are feasible to transfer into clinical practice. These should include the measurement of psychosocial outcomes as well as health status, health service use, cost-effectiveness and an assessment of implementation issues in order to inform the development of future self-care interventions for children/young people. In general, the diversity of individuals, families and communities has been neglected in the development of self-care support interventions. Consequently, there is a need for research that investigates what interventions are appropriate for individuals who face barriers due to disability, socio-economic status, education, culture, geography or gender. There has been a lack of a cumulative approach to research and opportunities to learn from studies investigating similar types of interventions but in different conditions appear to have been missed.

\section{Strengths and limitations}

This review has contributed to knowledge by evaluating selfcare support across different childhood long-term conditions and by focusing on a broad range of self-care support interventions whereas other reviews have mainly focused on single conditions and on particular types of intervention. In particular, it has aimed to examine the effectiveness of self-care support interventions in relation to their target, location of delivery and the medium used. An explicit and systematic approach was taken to searching and appraisal. However, there are a number of limitations to this review. Authors were not contacted for additional information about studies and nonEnglish language studies were not included in the review. Studies relating to asthma are over-represented in the review because there have been fewer randomized control trials conducted of self-care support interventions for diabetes and cystic fibrosis. In addition, the conclusions made from the review are not based on a meta-analysis but on a narrative synthesis. The self-care interventions reviewed are comprised of different elements and therefore it is difficult to assess the relative benefits of these different components rather than their global effect.

\section{Key messages}

- There is a lack of evidence on which to base the development of self-care programmes for children and young people.

- There is strong evidence of the effectiveness of interventions that target children/young people; use e-health or group-based methods; that are delivered in community settings.

- There is no evidence that interventions that focus on parents alone or are delivered only in hospital settings are effective.

- Well-designed trials of interventions are needed which are feasible to transfer into real-life settings and involve parents and children in their development.

\section{Acknowledgements}

This project was funded by the National Institute for Health Research Service Delivery and Organisation programme. The views and opinions expressed therein are those of the authors and do not necessarily reflect those of the National Institute for Health Research Service Delivery and Organisation programme or the Department of Health. 


\section{References}

Barlow, J., Wright, C., Sheasby, J. \& Turner, A. (2002) Selfmanagement approaches for people with chronic conditions: a review. Patient Education and Counseling, 48, 177-187.

Barlow, J., Swaby, L. \& Turner, A. (2007) Evaluation of a Pilot Supporting Parents Programme for Parents/Guardians of Children with Long Term or Life Limiting Conditions. Coventry University, Coventry, UK.

Bhogal, S. K., Zemek, R. L. \& Ducharme, F. (2006) Written action plans for asthma in children. Cochrane Database of Systematic Reviews, (3), CD005306.

Bower, P., Blakeman, T., Kennedy, A., Protheroe, J., Richardson, G., Rogers, A. \& Sanders, C. (2009) What Influences People to Self-Care? National Primary Care Research and Development Centre, University of Manchester, Manchester, UK.

Bruzzese, J. M., Bonner, S., Vincent, E., Sheares, B., Mellins, R. B., Levison, M. J., Wieseman, S., Du, Y., Zimmerman, B. J. \& Evans, D. (2004) Asthma education: the adolescent experience. Patient Education and Counseling, 55, 396-406.

Bury, M., Newbould, J. \& Taylor, D. (2005) A Rapid Review of the Current State of Knowledge Regarding Lay-Led Self-Management of Chronic Illness: Evidence Review. National Institute for Health and Clinical Excellence, London, UK.

Carroll, A. E., Marrero, D. G. \& Downs, S. M. (2007) The HealthPia ${ }^{\mathrm{TM}}$ GlucoPack Diabetes phone: a usability study. Diabetes Technology \& Therapeutics, 9, 158-164.

Centre for Reviews and Dissemination (2001) Undertaking Systematic Reviews of Research on Effectiveness: CRD's Guidance for Those Carrying Out or Commissioning Reviews. NHS Centre for Reviews and Dissemination, York, UK.

Christian, B., D’Auria, J. P. \& Fox, L. C. (1999) Gaining freedom: self-responsibility in adolescents with diabetes. Pediatric Nursing, 25, 255-260.

Christian, B. J. \& D’Auria, J. P. (2006) Building life skills for children with cystic fibrosis: effectiveness of an intervention. Nursing Research, 55, 300-307.

Cicutto, L., Murphy, S., Coutts, D., O’Rourke, J., Lang, G., Chapman, C. \& Coates, P. (2005) Breaking the access barrier: evaluating an asthma center's efforts to provide education to children with asthma in schools. Chest, 128, 1928-1935.

Corben, S. \& Rosen, R. (2005) Self-Management for Long-Term Conditions: Patients' Perspectives on the Way Ahead. Kings Fund, London, UK.

Couch, R., Jetha, M., Dryden, D. M., Hooton, N., Liang, Y. \& Durec, T. (2008) Diabetes Education for Children with Type 1 Diabetes Mellitus and Their Families, Evidence Report/Technology Assessment No. 166. Agency for Healthcare Research and Quality, Rockville, MD, USA.

D'Auria, J. P., Christian, B., Henderson, Z. \& Haynes, B. (2000) The company they keep: the influence of peer relationships on adjustment to cystic fibrosis during adolescence. Journal of Pediatric Nursing, 15, 175-182.
Davis, M. A., Quittner, A. L., Stack, C. M. \& Yang, M. C. (2004) Controlled evaluation of the STARBRIGHT CD-ROM Program for children and adolescents with cystic fibrosis. Journal of Pediatric Psychology, 29, 259-267.

Deakin, T. A., McShane, C. E., Cade, J. E. \& Williams, R. (2005) Group based training for self-management strategies in people with type 2 diabetes mellitus. Cochrane Database of Systematic Reviews, (2), CD003417.

Department of Health (2005) Self Care - A Real Choice: Self Care Support - A Practical Option. The Stationery Office, London, UK.

Department of Health (2006) Supporting People with Long Term Conditions to Self Care: A Guide to Developing Local Strategies and Good Practice. Department of Health, London, UK.

Department of Health (2008) Core Principles to Support Self-Care. Department of Health, London, UK.

Department of Health (2009) Healthy Lives, Brighter Futures. Department of Health, London, UK.

Department of Health, Department for Education and Skills (2004) National Service Framework for Children, Young People and Maternity Services: Children and Young People Who Are Ill. Department of Health, London, UK.

Eng, T. R. (2001) The E-Health Landscape: A Terrain Map of Emerging Information and Communication Technologies in Health and Health Care. The Robert Wood Johnson Foundation, Princeton, NJ, USA.

Espinoza-Palma, T., Zamorano, A., Arancibia, F., Bustos, M., Silva, J., Cardenas, C., De La Barra, P., Puente, V., Cerda, J.,

Castro-Rodriguez, J. \& Prado, F. (2009) Effectiveness of asthma education with and without a self-management plan in hospital. The Journal of Asthma, 46, 906-910.

Evans, R., Gergen, P., Mitchell, H., Kattan, M., Keresmar, C., Crain, E., Anderson, J., Eggleston, P., Malveaux, F. J. \& Wedner, H. J. (1999) A randomised clinical trial to reduce asthma morbidity amongst inner-city children: results of the national cooperative inner-city asthma study. The Journal of Pediatrics, 135, 332-338.

Flores, G., Briddon, C., Torres, S., Perez, R., Walter, T., Brotanek, J., Lin, H. \& Tomany-Korman, S. (2009) Improving asthma outcomes in minority children: a randomised, controlled trial of parent mentors. Pediatrics, 124, 1522-1532.

Franklin, V. L., Waller, A., Pagliari, C. \& Greene, S. A. (2006) A randomized controlled trial of Sweet Talk, a text-messaging system to support young people with diabetes. Diabetic Medicine, 23, 1332-1338.

Gammon, D., Arsand, E., Walseth, O., Andersson, N., Jenssen, M. \& Taylor, T. (2005) Parent child interaction using a mobile phone wireless system for blood glucose monitoring. Journal of Medical Internet Research, 7, e57.

Gary, T. L., Genkinger, J. M., Guallar, E., Payrot, M. \& Brancati, F. (2003) Meta-analysis of randomized educational and behavioural interventions in type 2 diabetes. The Diabetes Educator, 29, 488-501.

Glasscoe, C. A. \& Quittner, A. L. (2008) Psychological interventions for people with cystic fibrosis and their families. Cochrane Database of Systematic Reviews, (3), CD003148. 
Griffiths, K. \& Christensen, H. (2006) Review of randomised controlled trials of internet interventions for mental disorders and related conditions. The Clinical Psychologist, 10, 16-29.

Guendelman, S., Meade, K., Benson, M., Chen, Y. \& Samuels, S. (2002) Improving asthma outcomes and self-management behaviors of inner-city children: a randomized trial of the Health Buddy interactive device and an asthma diary. Archives of Pediatrics \& Adolescent Medicine, 156, 114-120.

Guendelman, S., Meade, K., Chen, Y. \& Benson, M. (2004) Asthma control and hospitalisations among inner-city children; results of an randomised trial. Telemedicine Journal and e-Health, 10, S6-S14. Hampson, S. E., Skinner, T. C., Hart, J., Storey, L., Gage, H., Foxcroft, D., Kimber, A., Shaw, K. \& Walker, J. (2001) Effects of educational and psychosocial interventions for adolescents with diabetes mellitus: a systematic review. Health Technology Assessment, 5, 1-79.

Higgins, J. P. T. \& Green, S. (eds) (2008) Cochrane Handbook for Systematic Reviews of Interventions. John Wiley, Chichester, UK.

Jan, R. L., Wang, J. Y., Huang, M. C., Tseng, M. S., Su, H. J. \& Liu, L. F. (2007) An internet-based interactive telemonitoring system for improving childhood asthma outcomes in Taiwan. Telemedicine Journal and e-Health, 13, 257-268.

Johnson, K. B., Ravery, R. D. \& Everton, A. (2001) Hopkins Teen Central: assessment of an internet based support system for children with cystic fibrosis. Pediatrics, 107, e24.

Kennedy, A., Rogers, A. \& Bower, P. (2007) Support for self care for patients with chronic disease. BMJ (Clinical Research Ed.), 335, 968-970.

Kirk, S., Beatty, S., Callery, P., Milnes, L. \& Pryjmachuk, S. (2010) Evaluating Self-care Support for Children and Young People with Long-term Conditions. National Institute for Health Research Service Delivery and Organisation Programme, Southampton, UK.

Lorig, K. R. \& Holman, H. (2003) Self-management education: history, definition, outcomes, and mechanisms. Annals of Behavioral Medicine, 26, 1-7.

Loveman, E., Frampton, G. K. \& Clegg, A. J. (2008) The clinical effectiveness of diabetes education models for Type 2 diabetes: a systematic review. Health Technology Assessment (Winchester, England), 12, 1-136.

Marshall, S. S., Haywood, K. \& Fitzpatrick, R. (2005) Patient Involvement and Collaboration in Shared Decision-Making: A Review. Patient-assessed Health Instruments Group, Department of Public Health, University of Oxford, Oxford.

Murray, E., Burns, J., See Tai, S., Lai, R. \& Nazareth, I. (2005) Interactive Health Communication Applications for people with chronic disease. Cochrane Database of Systematic Reviews, (4), CD004274.

Norris, S. L., Nichols, P. J., Caspersen, C. J., Glasgow, R. E., Engelgau, M. M., Jack, L. Jr, Snyder, S. R., Carande-Kulis, V. G., Isham, G. J., Garfield, S., Briss, P. \& McCulloch, D. (2002) Increasing diabetes self-management education in community settings: a systematic review. American Journal of Preventive Medicine, 22 (Suppl. 4), 39-66.

Palermo, T. M., Long, A. C., Lewandowski, L., Drota, D., Quittner, A. L. \& Walker, L. S. (2008) Evidence-based assessment of health-related quality of life and functional impairment in pediatric psychology. Journal of Pediatric Psychology, 33, 983-996.

Prout, A., Hayes, L. \& Geldner, L. (1999) Medicines and maintenance of ordinariness in the household management of childhood asthma. Sociology of Health \& Illness, 21, 137-167.

Rogers, A., Gately, C., Kennedy, A. \& Sanders, C. (2009) Are some more equal than others? Social comparison in self-management skills training for long-term conditions. Chronic Illness, 5, 305-317.

Stevens, C. A., Wesseldine, L. J., Couriel, J. M., Dyer, A. J., Osman, L. M. \& Silverman, M. (2002) Parental education and guided self-management of asthma and wheezing in the preschool child: a randomised controlled trial. Thorax, 57, 39-44.

Sullivan, S., Weiss, K., Lynn, H., Mitchell, H., Kattan, M. \& Gergen, P. (2002) The cost-effectiveness of an inner-city asthma intervention for children. The Journal of Allergy and Clinical Immunology, 110, 576-581.

Toelle, B. \& Ram, F. S. F. (2004) Written individualised management plans for asthma in children and adults. Cochrane Database of Systematic Reviews, (1), CD002171.

Trollvik, A. \& Severinsson, E. (2005) Influence of an asthma education program on parents with children suffering from asthma. Nursing \& Health Sciences, 7, 157-163.

Upton, P., Eiser, C., Cheung, I., Hutchings, H. A., Jenney, M., Maddocks, A., Russell, I. T. \& Williams, J. G. (2005) Measurement properties of the UK-English version of the Pediatric Quality of Life Inventory 4.0 (PedsQL) generic core scales. Health and Quality of Life Outcomes, 3, 22.

Van der Meer, V., van Stel, H., Detmer, S. B., Otten, W., Sterk, P. \& Sont, J. K. (2007) Internet-based self-management offers an opportunity to achieve better asthma control in adolescence. Chest, 132, 112-119.

Wade, T. A., Watson, M. D., Gillespie, C., Thomas, N., Filuk, S., McColm, J., Piwniuk, M. \& Becker, A. (2009) Small group, interactive education and the effect on asthma control by children and their families. Canadian Medical Association Journal, 181, 257-263.

Walders, N., Kercsmar, C., Schluchter, M., Redline, S., Kicher, H. \& Drotar, D. (2006) An interdisciplinary intervention for undertreated asthma. Chest, 129, 292-299.

Wanless, D. (2002) Securing Our Future Health: Taking A Long-Term View (Final Report). HM Treasury, London, UK.

Wesseldine, L. J., McCarthy, P. \& Silverman, M. (1999) Structured discharge procedure for children admitted to hospital with acute asthma: a randomised controlled trial of nursing practice. Archives of Disease in Childhood, 80, 110-114.

Wolf, F., Guevara, J. P., Grum, C. M., Clark, N. M. \& Cates, C. J. (2002) Educational interventions for asthma in children. Cochrane Database of Systematic Reviews, (4), CD000326.

Yorke, J. \& Shuldham, C. (2005) Family therapy for asthma in children. Cochrane Database of Systematic Reviews, (2), CD000089.

Yorke, J., Fleming, S. L. \& Shuldham, C. (2005) Psychological interventions for children with asthma. Cochrane Database of Systematic Reviews, (4), CD003272. 